\title{
Burden on Parenting of Children with Special Needs: Review Article
}

\author{
Amel Ahmed Hassan ${ }^{1 *}$, Amal Mohammed Hamid ${ }^{2}$, Nagla Hassan Eltayeb ${ }^{3}$ \\ ${ }^{1}$ Assistant Professor of Community Health Nursing-Faculty of Medical Technical Sciences-Department of Nursing- Alzaiem Alazhari \\ University-Khartoum North- Sudan \\ ${ }^{2}$ Assistant Professor of Obstetrics \& Gynaecological Nursing- Faculty of Medical Technical Sciences-Department of Nursing- \\ Alzaiem Alazhari University-Khartoum North- Sudan \\ ${ }^{3}$ Assistant Professor of Community Health Nursing- Department of Nursing-Hayat University College- Khartoum-Sudan
}

Article History

Received: 28.01.2021

Accepted: 09.03.2021

Published: 22.03.2021

Journal homepage:

https://www.easpublisher.com

\begin{abstract}
A stress among parenting caregivers of children with special needs is pervasive and lead to difficulty of interacting with community and negative psychological consequences. This review provide comprehensive summary to explain subjective and objective burden on parenting caregivers who caring of children with different intellectual developmental disabilities, their treatments and specific strategies to deal with such cases. Keywords: Burden, caregivers, children.
\end{abstract}

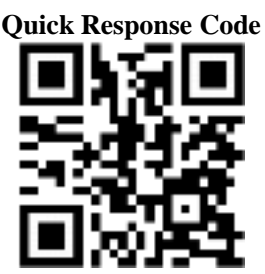

Copyright (C) 2021 The Author(s): This is an open-access article distributed under the terms of the Creative Commons Attribution 4.0 International License (CC BY-NC 4.0) which permits unrestricted use, distribution, and reproduction in any medium for non-commercial use provided the original author and source are credited.

\section{INTRODUCTION}

Mental health is more than the mere lack of mental disorders. It includes subjective well-being, perceived self-efficacy, autonomy, competence, intergenerational dependence and recognition of the ability to realize one's intellectual and emotional potential. It is a state of well-being whereby individuals recognize their abilities, are able to cope with the normal stresses of life, work productively and fruitfully, and make contributions to their communities. In addition to this, mental health is about enhancing competencies of individuals and communities and enabling them to achieve their self-determined goals. Such individuals function well in society, are accepted within a group, and are generally satisfied in their lives. In contrast, mental illness is a disorder, which is characterized by disturbances in persons' thought, emotion, behavior and relationship. In other word, mental illness is a health problem that significantly affects how a person feels, thinks, behaves, and interacts with other people [1]. According to WHO there are greater than one billion people with disabilities; that includes about 15 percent of the world's population or approximately one in seven people. An estimated 93 million children, or about one in twenty of those below 15 years of age, live with moderate or severe disability. This includes autism spectrum disorder (ASD), cerebral palsy, intellectual disability (ID), and developmental delays, among others Children with intellectual developmental disabilities (IDD) are at risk for health problems, psychopathological and behavioral problems [1]. The UNICEF reported that I billion people have a disability; at least 1 to 10 is a child (100 million children); and $80 \%$ live in developing countries [2]. An intellectual disability is the most common developmental disabilitynearly 6.5 million people in the United States have some level of ID. More than 545.000 are ages 6-21 [3, 4]. The mental health problems of children greatly impact the social, familial, educational and leisure domains of their parents' lives, creating challenges and burden for them. Many studies have in fact shown that parents of children with psychiatric disorders experience both objective and subjective burden. The objective burden refers to the disrupted daily life routines of the family, and to the limitations on the social, occupational, and familial domains of quality of life, which arise as a result of the child's disorder. The subjective burden refers to the relatives' various psychological reactions, such as anxiety, frustration and depression. It should be 
noted that the parents' emotional reactions could affect the child's symptomatology, which can in turn increase the parents' emotional experience. Previous studies have shown that objective and subjective aspects of family burden are correlated with patient characteristics, such as severity of symptoms and number of hospitalizations and with family environment and support. In addition, variables related to illness perception, such as insight into the illness and internalization of the stigma by parents were also found to be positively associated with the family burden experienced by parents of children with psychiatric disorders [5].

\section{INTELLECTUAL DEVELOPMENTAL DISABILITIES}

Parents of children with intellectual and/or developmental disabilities are presented with a unique set of challenges associated with providing care for their children. Depending upon the nature and severity of the disability, the child may require significant personal care and monitoring to ensure his or her wellness and safety. Parents are usually the primary provider of this care. Given other responsibilities that parents typically have in relation to maintaining stability for their family, the additional responsibility of providing significant levels of care for their child indefinitely may task parents' ability to maintain balance in their own lives [6,7]. Siblings have the longest-lasting familial relationship, when a disability is present; siblings may fulfill unique roles related to their brother or sister with (IDD) such as caregivers and advocates [8]. Parents of children with IDD report higher levels of stress than parents of typically developing children. Factors related to levels of increased stress include financial challenges, level of parental education and social support, psychological distress, child's diagnosis, and child behavioral problems [9].

\section{DEVELOPMENTAL DISABILITY}

The parents and families of children with DDs experience distress during and after the diagnosis. Specifically, those parents who are caring for children with DDs face great distress. Children with DDs cause or involve themselves in problems in the community or at school. Children with DDs and their mothers have received lower quality of life (QoL) scores than their normal control group peers. Inada reported that both the psychological and social QoL of children with pervasive DDs were significantly lower than that of the general population. Markowitz et al., also revealed that the QoL of caregivers of children with autism spectrum disorder was already impaired before the diagnosis [1].

\section{INTELLECTUAL DISABILITY}

Intellectual disability is a health condition that often requires special healthcare needs They are more likely to experience somatic complaints, social problems, attention problems, thought problems, delinquent behavior, aggressive behaviors or internalizing or externalizing problem and are also more likely to be at higher risk of a mental health disorder than children without ID; 30 to $50 \%$ of children with ID have a mental health disorder compared with 8 to $18 \%$ of those without. Caregivers of children with developmental disabilities experience higher levels of distress than caregivers of children without disabilities. ID affects about $1.8 \%$ of children and youth and is more prevalent in men than in women. Moreover, it is more common in low income and middle-income countries than in high income countries [1]. One study in Taiwan demonstrated that caregivers of family members with an intellectual disability reported a lower quality of life than caregivers of family members with mental illness [2]. Multiple studies from India suggest that family members of patients with severe intellectual disorder face considerable caregiver burden and suffer from psychological distress, also experience poor QoL and face considerable stigma because of their association with a person with intellectual disorder [3].

\section{TYPES OF DisABILITIES NEURODEVELOPMENT DISORDERS}

Intellectual Disabilities: includes Intellectual Disability (Intellectual Developmental Disorder), developmental delay, unspecified Intellectual Disability (Intellectual Developmental Disorder), mental retardation, Down syndrome and epilepsy.

Communication Disorders: includes language disorder and speech sound disorder (previously Phonological Disorder).

Autism Spectrum Disorder: includes autism spectrum disorder.

Attention-Deficit/Hyperactivity Disorder: includes attention deficit/Hyperactivity disorder, other specified attention-deficit/Hyperactivity disorder and unspecified attention-deficit/Hyperactivity disorder.

Specific Learning Disorder: includes Specific Learning Disorder.

Motor Disorders: Includes developmental coordination disorder.

\section{OTHER NEURODEVELOPMENT DISORDERS}

Other specified neurodevelopment and unspecified neurodevelopment disorder.

\section{DISORDERCHARACTERISTICS}

Mental disorder refers to "a health condition characterized by significant dysfunction in an individual's cognitions, emotions, or behaviors that reflects a disturbance in the psychological, biological, or developmental processes underlying mental functioning". Intellectual disability involves 
impairments of general mental abilities that impact adaptive functioning in three domains, or areas.

These domains determine how well an individual copes with everyday tasks: The conceptual domain includes skills in language, reading, writing, math, reasoning, knowledge, and memory, the social domain refers to empathy, social judgment, interpersonal communication skills, the ability to make and retain friendships, and similar capacities and the practical domain centers on self-management in areas such as personal care, job responsibilities, money management, recreation, organizing school and work tasks. While intellectual disability does not have a specific age requirement, an individual's symptoms must begin during the developmental period and are diagnosed based on the severity of deficits in adaptive functioning. The disorder is considered chronic and often co-occurs with other mental conditions like depression, attention-deficit/hyperactivity disorder, and autism spectrum disorder $[4,5]$.

\section{NEURODEVELOPMENT DISORDERS}

The degrees of intellectual disability include mild, moderate, and severe and profound intellectual disability. Intellectual disability is a public concern due to the number of people affected by this condition with consideration of the increased demand of specialized medical, psychosocial, and educational services required to improve their quality of life. According to recent reviews and meta-analysis, globally, about $1 \%$ of general population is affected by intellectual disability. Child/adolescent population has higher prevalence (18.30/1000) than the adult population (4.94/1000). Furthermore, it is estimated that about $1 \%$ of children between the ages 3 and 10 years are affected by intellectual disability worldwide Study done in Kenya showed that high proportion $(40 \%)$ of children was suffering moderate intellectual disability. Children with moderate intellectual disability tend to have remarkable limitations in meeting expected standards of personal independence and social responsibility in different aspects of daily life, especially when they start school. Therefore, when child starts to show slow academic achievements, he/she is referred for psychological evaluation [6].

\section{DISORDER OF INTELLECTUAL DEVELOPMENT, MILD}

A mild disorder of intellectual development is a condition originating during the developmental period characterized by significantly below average intellectual functioning and adaptive behavior that are approximately two to three standard deviations below the mean (approximately $0.1-2.3$ percentile), based on an appropriately normed, individually administered standardized tests or by comparable behavioral indicators when standardized testing is unavailable. Affected persons often exhibit difficulties in the acquisition and comprehension of complex language concepts and academic skills. Most master basic selfcare, domestic, and practical activities. Persons affected by a mild disorder of intellectual development can generally achieve relatively independent living and employment as adults but may require appropriate support.

\section{DISORDER OF INTELLECTUAL DEVELOPMENT, MODERATE}

A moderate disorder of intellectual development is a condition originating during the developmental period characterized by significantly below average intellectual functioning and adaptive behavior that are approximately three to four standard deviations below the mean (approximately $0.003-0.1$ percentile), based on appropriately normed, individually administered standardized tests or by comparable behavioral indicators when standardized testing is unavailable. Language and capacity for acquisition of academic skills of persons affected by a moderate disorder of intellectual development vary but are generally limited to basic skills. Some may master basic self-care, domestic, and practical activities. Most affected persons require considerable and consistent support in order to achieve independent living and employment as adults.

\section{DISORDER OF INTELLECTUAL DEVELOPMENT, SEVERE}

A severe disorder of intellectual development is a condition originating during the developmental period characterized by significantly below average intellectual functioning and adaptive behavior that are approximately four of more standard deviations below the mean (less than approximately the 0.003rd percentile), based on appropriately normed, individually administered standardized tests or by comparable behavioral indicators when standardized testing is unavailable. Affected persons exhibit very limited language and capacity for acquisition of academic skills. They may also have motor impairments and typically require daily support in a supervised environment for adequate care, but may acquire basic self-care skills with intensive training [7].

\section{DEVELOPMENTAL LEARNING DISORDER}

Developmental learning disorder is characterized by significant and persistent difficulties in learning academic skills, which may include reading, writing, or arithmetic. The individual's performance in the affected academic skill(s) is markedly below what would be expected for chronological age and general level of intellectual functioning, and results in significant impairment in the individual's academic or occupational functioning. It first manifests when academic skills are taught during the early school years. Also is not due to a disorder of intellectual development, sensory impairment (vision or hearing), neurological or motor disorder, lack of availability of 
education, lack of proficiency in the language of academic instruction, or psychosocial adversity.

\section{ATTENTION DEFICIT HYPERACTIVITY DISORDER}

Attention deficit hyperactivity disorder is characterized by a persistent pattern (at least 6 months) of inattention and/or hyperactivity-impulsivity, with onset during the developmental period, typically early to mid-childhood. The degree of inattention and hyperactivity-impulsivity is outside the limits of normal variation expected for age and level of intellectual functioning and significantly interferes with academic, occupational, or social functioning. Inattention refers to significant difficulty in sustaining attention to tasks that do not provide a high level of stimulation or frequent rewards, distractibility and problems with organization. Hyperactivity refers to excessive motor activity and difficulties with remaining still, most evident in structured situations that require behavioral self-control. Impulsivity is a tendency to act in response to immediate stimuli, without deliberation or consideration of the risks and consequences. The relative balance and the specific manifestations of inattentive and hyperactive-impulsive characteristics vary across individuals, and may change over the course of development. In order for a diagnosis of disorder the behavior pattern must be clearly observable in more than one setting.

\section{AUTISM SPECTRUM DISORDER}

Autism spectrum disorder is characterized by persistent deficits in the ability to initiate and to sustain reciprocal social interaction and social communication, and by a range of restricted, repetitive, and inflexible patterns of behavior and interests. The onset of the disorder occurs during the developmental period, typically in early childhood, but symptoms may not become fully manifest until later, when social demands exceed limited capacities. Deficits are sufficiently severe to cause impairment in personal, family, social, educational, occupational or other important areas of functioning and are usually a pervasive feature of the individual's functioning observable in all settings, although they may vary according to social, educational, or other context. Individuals along the spectrum exhibit a full range of intellectual functioning and language abilities [7,8]. These deficits can be a major source of stress and frustration for parents. The number of children diagnosed with ASD worldwide has and is still growing to 1 in 59 children in 2018 from 1 in 68 in two years previously [9]. Children with ASD often require additional primary care as well as more specialized and long-term medical care. Functional limitations may necessitate structural or technical modifications in the physical home environment. Also require parents to seek educational and recreational accommodations to ensure that the child has opportunities that are equal to those of a child [10].

\section{CEREBRAL PALSY (CP)}

(CP) is a chronic condition defined as a set of functional limitations due to alterations in the development of the central nervous system, it is estimated that the incidence of this disorder worldwide is between 2 to 2.5 cases per 1,000 births. Although motor malfunction is the cardinal limitation of $\mathrm{CP}$, the severity of disability is also determined by the presence of sensory, cognitive and social impairments leading to significant limitations in self-care functions related to food, personal hygiene and mobility. For these reasons $\mathrm{CP}$ can be taken as a prototype of childhood disability. The limitations of those affected can result in demands and requirements for long-term care, which can greatly exceed the normal requirements associated with the early stages of child development. While care is part of parenting, it can often generate a significant burden when the requirements are excessive and long lasting. This excessive responsibility may adversely affect the physical and psychological health of caregivers, affecting their social, cultural and professional lives and possibly reducing their quality of life [11]. The first aspect of treating children with Cerebral Palsy is ensuring that the families have heard and come to some level of acceptance that their children have some problem called Cerebral Palsy, which is permanent and will not go away. The limitations of the child with $\mathrm{CP}$ can result in requirements for long term care, far exceeding the usual needs of children as they develop, or the expectations of their families as they parent [12].

\section{DOWN SYNDROME (DS)}

DS is developmental disability associated with various health problems such as congenital heart disease, hearing loss and endocrine disorders [13]. Mothers of children with Down syndrome display better psychological wellbeing than mothers of similarly-aged children with other types of intellectual developmental disabilities. Also have less pessimism about their child's future, more closeness in the relationship with their child, and fewer depressive symptoms and more likely to perceive that the child reciprocated feelings of closeness compared with mothers of children with other types of intellectual developmental disabilities. Mothers of children with Down syndrome have reported less conflicted family environments, less stress and lower level of divorce, more satisfaction with their social supports, more optimism and acceptance of their child's disability but increasing the degree of dependence affecting QoL and caregivers' health [14-16].

\section{EPILEPSY}

Epilepsy is a treatable but potentially devastating condition emerges in the first year of life $[17,18]$ in low resource areas where access to treatment is not readily available. It has been estimated that about 3-4 million Africans suffer from epilepsy with $80 \%$ of them having no access to modern medical facilities. The disease is associated with stigma which is not only limited to the patient but also includes other family 
members. Caregiver's with epileptic child develop symptoms such as mood swings, fatigue, headaches, joint and muscle pains, marital and family conflicts, and financial problems. Reports of studies carried out in various parts of the world have indicated that caring for patients with epilepsy is associated with emotional distress, burden, impaired quality of life in caregivers and poor outcome of the disease in both patients and caregivers. Social support, provision of psychoeducation, accessible and affordable modern health care facilities lower levels of depression, stress, and anxiety to both patients with epilepsy and caregivers [19, 20].

\section{MENTAL RETARDATION}

Mental retardation remains the world problem particularly for developing countries. It is estimated that the incidence of severe MR approximately $0.3 \%$ of total population and nearly $3 \%$ the IQ is fewer than 70 . About $0.1 \%$ of those children require treatment, guidance and prolonging supervision throughout their life. MR remains a dilemma, leading anxiety for families and communities because the diagnosis, treatment, and its prevention are indistinct [21]. Mental retardation is a result of pathologic process in the brain that illustrates the limitations of intellectual and adaptive function, but it is not a disease. May occur with or without disruption of mentally or physically disorders [22]. It is classified into three groups including mild (IQ between 52-68 Binet scale), moderate (IQ between 36-51 Binet scale), severe (IQ between 20-30 Binet scale) [23].

\section{BURDEN ON CAREGIVERS}

Caregivers face unique challenges in their role of children with IDD. These challenges include extra financial costs, chronic stress, social isolation, and perhaps most importantly, additional responsibilities of navigating multiple social service systems [24]. The family of children with IDD experience burden due to various problems encountered with regard to financial conditions, routine family interaction, and leisure, physical and mental health of other members of the family caused by the handicapped family member. The psychological trauma of the family members is generally more profound.

One study reported that parental burden in the form of interfaces in their family routine or leisure and recreational, which even resulted in social, partial familial and emotional problems in the home setting of individuals with mental handicap. The mothers of mentally handicapped children reported higher social burden than those of the physically handicapped children. In a study conducted by Mulroy et al., focusing on sibling impact of having a teenager with ID, parents indicated that the toddler (TD) sibling experienced disadvantages due to having a sibling with ID. These disadvantages included the parents having less time to spend with the TD child, decreased number of family activities, diminished financial resources, increased care giving responsibilities placed on the TD child, and decreased peer acceptance [25, 26].

\section{SOCIAL BURDEN}

Family stigma has been proposed as an efficient way of referring to the prejudice and discrimination experienced by individuals related to someone experiencing mental health issues and can be as harmful as the symptoms, leading to family discord, job discrimination, and social rejection. Mak and Cheung demonstrated a positive association between caregivers' feelings of stress and subjective burden and affiliate stigma among caregivers of children with intellectual disability $[25,26]$. A natural consequence of increased time strain and financial pressure on caregivers is a reduction in the quantity or quality of social interactions such as marital, peer, and community relationships. Parenting a child with an ASD has been shown to potentially contribute to stress on the caregivers' spousal relationship, leading to decreased marital satisfaction; one United States of America (USA) study demonstrated greater likelihood for divorce in parents of children with an ASD $24 \%$ as opposed to the standard rate of $14 \%$ [27]. Indeed recent evidence shows that stigma is associated with burden, marital satisfaction and social exclusion in parents of children with IDs. Stigma refers to the impact of negative attitudes and behaviors from the general public on individuals and often results in negative psychological and physical health for the stigmatized individual [26]. Parents of children with disabilities are vulnerable position of associative stigma in form of shame, embarrassment, and social censure due to the presumably causal relationship between parental practices and children's bodies, behaviors, and development [28].

\section{PSYCHOLOGICAL BURDEN}

Parents caring for children with intellectual disabilities (IDs; e.g. Autism and Down syndrome) often report higher depressive symptoms when compared with parents of typically developing children [29]. Burden may be higher in families raising children with disability (CWD), as a result of the demands of caring for the CWD, as well as other children in the family. Stresses can originate from family problems, child behavioral and social issues, or lack of resources and support. Research shows that the type of disability is related to the stress and subsequent burden experienced by parents. Specifically, Parents of children with autism report more stress than parents of other disabilities because autism is a debilitating, life-long neuro-developmental disorder characterized by social deficits, restricted interests and repetitive behaviors' and IQ less than 70 and limitations in adaptive behavior present before 18 years [30,31].

Roles within the family may need to be restructured and the resulting strain may manifest itself in family problems, including high rates of dissertation, 
divorce, family quarrelling and marital breakdown; establishing and maintain satisfying social networks. As the child grows up and disability becomes quite noticeable by others, parents face a very distressing predicament of social embarrassment and stigma. This may lead to isolation of the child even within the family, the child may be restricted from coming out when relatives and friends visit the house or may be left back at home when parents go out [31].

National Health Interview Survey data indicate higher levels of depressive symptoms and health issues and poorer access to health care for some caregivers of children with IDD in comparison with other families [32]. The relationship between caring for these children and psychological distress for their parents has been studied but mainly in developed world settings. Some studies have been conducted in Low and Middle Income Countries such as Kenya, Kuwait, Qatar and India which similarly report rates of $47-50 \%$ prevalence of psychological disorders amongst these parents. Parenting such children may lead to difficulties with family functioning, parenting stress, and different parenting style compared to parenting normally developing children. Several studies highlight the child, parental and environmental factors which predict psychological distress amongst parents of intellectually disabled children. Factors include: lower socioeconomic status, single motherhood, feminine gender, perceived burden of care, lack of psychosocial support, knowledge of child's disability and having more than one child with a disability in the family. Autism is more likely to cause high psychiatric symptomatology among parents ${ }^{(33)}$. The literature suggests that these carers' have a greater propensity to stress, anxiety, depressive symptoms [44]. Parents undergo chronic sorrow which is periodic in nature, precipitated by child's deviants from normal performance. The intensity of reaction was related to the particular developmental stage and the individual coping strengths of the family. Feelings of depression are common, particularly when realization of the child's retardation is recent. Some mother's react to the retarded child as if he had died and manifest the typical grief reaction associated with the loss of a loved one. Mothers are more active in their child's care and bear most of the burden associated with it. They tend to give themselves little time to adjust, as the child with the disability continues to require ongoing care. Mainly mothers have difficulty on child care taking, difficulty of feeding, bathing and dressing and caretaking time. Many mothers suffer loss of self-esteem when they recognize retardation in their child. A serious defect, and may feel responsible for disappointing her mate and other family members by presenting them with a defective child. Closely allied to loss of self-esteem and with the feeling of shame they may anticipate social rejection, pity or ridicule and related loss of prestige. Some studies shows that mothers have to tend to do more work than their fair share and their activities are often restricted [35-37].
Levels of caregiver strain are often suggested to differ by diagnostic group. Across multiple studies, caregivers of children with ASD report higher levels of strain than parents of children with DD, children with attention deficit hyperactivity disorder, children with emotional and behavioral disorders (EBD), and children with other healthcare needs. Study done by Abbeduto et al. Found that parents of children with ASD had higher levels of strain when compared with parents of children with Down syndrome, but lower than those of children with Fragile X [38].

In India, majority of the mentally ill persons are cared by family which stigmatizes the family as well. Other studies found that female of the patient and a younger age of both patient and caregiver enhanced associative stigma, and caregivers' stigma increased with male gender, literacy, rural residence [39]. The effects of stigma are strong and are manifested in the realm of; employment, housing, education, transportation, medical care, making and keeping friends, lower self-esteem and damaged family relationships [40].

\section{FINANCIAL BURDEN}

Children with ASD or ID (ASD/ID) have more challenging behavior, sleep disorders and psychopathologies than typically developing children. Their mothers have increased expenses, more stigma and less informal support which may contribute to their poorer psychiatric health after the birth of their child. Their poorer psychiatric health after the birth might also result from higher rates of treatment episodes for psychiatric disorders before the birth [41]. Families with a person who has IDD often experience financial hardship because these families may work fewer hours, quit working, or experience high care costs [42]. Medical costs for children 0-4 years with Down syndrome (DS) are 12-13 times higher than for those without DS and higher still when the diagnosis includes congenital cardiac conditions. Families are seeking early intervention, medical, and therapeutic services for their child; ideally, care for infants and children should occur within a continuous, co-ordinate and culturally effective system accessible for families and delivered by experienced healthcare professionals [43].

\section{PHYSICAL BURDEN}

A body of evidence exists internationally to suggest that providing care to a family member with intellectual disability within the family home can have an adverse effect upon carers' physical and psychological health. A large-scale study comparing health outcomes of carers' of children with intellectual disability with age-matched non-care giving peers showed that carers' were significantly more likely to report experiencing higher rates of arthritis, diabetes, high blood pressure, osteoporosis, cardiovascular 
diseases, obesity and activity limitation than their noncare giving peers [44].

Children may require special equipment, medical care, and programming and at the same time; family income may be reduced because care giving responsibilities make it difficult for two parents to work outside the home [45].

\section{SOCIAL SUPPORT}

Social support is broad term encompassing a variety of constructs, including support perceptions (perceived support) and receipt of supportive behaviors' (received support). Mothers of children with disability have the higher the perception of economic situation and income adequacy, parenting social support, and religious practices, and the lower the symptoms of depression and found that minority mothers showed the higher the religious coping, the lower the symptoms of depression. Some studies found that the presence of social support significantly predicts the individual's ability to cope with stress and it was knowing that they are valued by others is an important psychological factor in helping them to forget the negative aspects of their lives, and thinking more positively about their environment [45].

Specialized education and interventions can greatly benefit children with DS ages 3-21 years. These services are publicly supervised, provided free to families in natural environments (e.g. home or daycare) by qualified personnel, are individualized to meet the developmental needs of children with significant delays. Additionally, Children's Medical Services (CMS), a Florida statewide network of physicians and healthcare, providers funded through Federal Title V legislation, assists with referral, care co-ordination, and a range of medical, therapeutic and supportive services for eligible children (by income and medical diagnosis). Although additional community-based and private intervention services and supports exist (e.g. parenting and disability-specific support groups, recreation, therapy services), access is limited by geography, programme capacity, costs and lack of publicity [46]. This meant transferring people suffering from mental illness from institutions to the local community. A recently published Swedish study revealed that family members spent an average of 22.5 hours/ week on carerelated activities [47]. In Sweden, the political strategy was to structure mental health care in order to enable mentally ill patients to live as normal a life as possible ${ }^{(48)}$. In Perkins' case study, experience of one caregiver was described increasingly small network of social support, the difficulty managing extensive care giving demands and a decrease in resiliency to stress $[49,51]$.

Care givers specially mothers of children with developmental disabilities experienced greater distress because of the child's behavior problems, dependence on care, anxiety and poor communication skills. Families supporting a child with intellectual disability are significantly more likely to experience social isolation, poverty and the range of environmental adversities associated with poverty. This gives cause for concern as poverty has been linked to high levels of stress and low mental health. social support acts as a buffer to stress - decreasing loneliness, facilitating coping and having beneficial physiological effects that lead to improved health and wellbeing $[52,53]$.

Social support for parents caring for child with disabilities can take many forms, both informal and formal. Formal supports relate to funded initiatives to help alleviate parental stress and caregiver burden through providers contracted with the government. Informal support relates to support from family, peers, and the wider community. The perceived usefulness, reliability and flexibility of these supports can impact on caregiver's wellbeing and QoL. Those who report higher levels of perceived social support from friends, family, support organizations, and their communities as a whole show lower levels of stress and higher levels of QoL compared to those who report low levels of perceived social support [54].

\section{PARENTS- CHILD INTERACTIVE THERAPY}

Disruptive behavior among preschool-age children is a growing concern because of its high prevalence and poor prognosis. The prevalence of disruptive behavior disorders, including oppositional defiant disorder (ODD) and conduct disorder, is estimated at between $2 \%$ and $16 \%$ according to American Psychiatric Association [APA], and even higher rates are reported among children with mental retardation (MR). Recent studies indicate that parents rate children with MR significantly higher on measures of disruptive behavior than typically developing children. For many children with MR, treatment of ODD is imperative. Disruptive behavior often prevents these children from participating in important educational and community activities as well as rehabilitation for associated disorders (e.g., speech therapy). Disruptive behavior also contributes to physical safety concerns, higher need for supervision, reduced opportunities for independent functioning, and disrupted interpersonal relationships. More recently, Stepping Stones Triple P (SSTP), an adaptation for children with MR of the evidence-based Positive Parenting Program, was examined with multiple measures in a randomized controlled trial. Children (ages 2 to 7) with either intellectual or adaptive functioning scores 2 standard deviations below the mean and parent-reported behavior problems were assigned to a waitlist control or 10-session, individually delivered SSTP. Parents in the treated group reported fewer child behavior problems after treatment than control parents [53].

Autism is usually recognized between 4 and 6 years of age, and in some cases even later. Only a small proportion of children are diagnosed before the age of 
3. In addition, being diagnosed does not automatically mean that the child receives proper support. There are too few professionals specializing in therapy and developmental support for children with ASD. There is no governmental programme of intensive early intervention for these children. As a result, only a small proportion of children and parents receive appropriate support. Specialized services are very expensive. Families with low socioeconomic status (SES) and those living in small towns or villages have very limited access to therapeutic help. When the child has an intellectual disability, there may also be increased difficulties in care demands [54, 55]. Psychiatrists and mental health professionals need to collaborate actively with the local media to ensure that an appropriate social message is passed on. Education provides accurate information to the public about mental illness. Contact entails positive social interaction with persons with mental illness [56, 57]. Children with intellectual disability have poorer health and shorter life spans than the general population, as well as high levels of unrecognized disease and inadequate health screening and promotion lead to Poor performance in physical, psychological or social, needs to be compensated by the caregivers. This leads to unavoidable stress and psychological trauma among the families. In a country like India where care provided for MR is mainly home based and alternate support systems such as day care centers, weekend care and special schools are meager the burden of care can be enormous [58,59].

\section{COPING STRATEGIES}

Beyond the contributions of diagnosis, a number of parent and contextual factors have been identified as playing a critical role in the levels of experienced strain among caregivers of children with ASD and DD. Parent factors include a parent's use of coping strategies and their locus of control, which help account for variations in level of strain. The double ABCX model, for example, has been highly researched and has resulted in a substantial ability to predict levels of strain among caregivers of children with IDD. Caregivers' assessment of the difficulty of care giving tasks has also been a frequently cited contributor to level of strain. Contextual factors which may impact the experience of caregiver strain include socioeconomic conditions (typically measured by maternal education or family income and amount of social support) [48]. This model of coping to be the central process in the family's efforts to adapt to a crisis using personal resources of family members, internal resources of the family system and social support from resources external to the family. Personal resources include, among others, physical and emotional health, and financial well-being, education, and personality characteristics of individual family members. The most important internal resources of the family system are cohesion and adaptability, pattern of communication and mutual support. The third type of resources includes social support from people and institutions outside the family and from the family's social network. Family adaptation is a positive response to stressors using effective coping strategies. Research on coping in families of children with developmental difficulties typically focused on specific burdens faced by parents rather than on individual differences in coping [57].

A psycho-social stress and resilience model derived from the transactional theory of coping and stress has been used to explain the relationship between impacts of stressors associated with caring for a child with an intellectual disability on family well-being used this model, which emphasizes the cognitive appraisals people bring to situations and the secondary and consequent appraisals of the coping resources they can call upon to deal with their circumstances. They found that coping was differentiated according to sex, life stage and family structure. A mother of children with mental retardation also uses different types of coping strategies to overcome with the problem. Denial, Rehearsal of outcome, finding a purpose and seeking emotional support were the commonly utilized coping styles by the mothers of mentally handicapped children [58].

Having a child with ID has an impact on all family members, with both parents and siblings having to adjust and adapt. Much of the parental adjustment research has focused on mothers of children with ID, with findings indicating that they experience higher levels of stress and depression compared to mothers of typically developing children and typically engage in more of the daily living routines associated with having a child with ID than their partner or spouse. Culture or ethnicity, which is often a proxy for culture, has been found to play a role in overall family adjustment [51]. The existing research describes a decrease in resources, social support and parent resiliency when faced with multiple care giving responsibilities, and these factors are known to have an impact on the entire family [52].

\section{ABC-X MODEL OF FAMILY STRESS AND COPING}

The double ABCX model determines the relationship between stressful events and crises within families [59]. Caregivers' assessment of the difficulty of care giving tasks has also been a frequently cited contributor to level of strain. Contextual factors which may impact the experience of caregiver strain include socioeconomic conditions typically measured by maternal education or family income and amount of social support [48]. This model of coping to be the central process in the family's efforts to adapt to a crisis using personal resources of family members, internal resources of the family system and social support from resources external to the family. Personal resources include, among others, physical and emotional health, and financial well-being, education, and personality characteristics of individual family members. The most important internal resources of the family system are 
cohesion and adaptability, pattern of communication and mutual support. The third type of resources includes social support from people and institutions outside the family and from the family's social network. Family adaptation is a positive response to stressors using effective coping strategies. Research on coping in families of children with developmental difficulties typically focused on specific burdens faced by parents rather than on individual differences in coping [58].

The development of the ABC-X model was influenced by the emergence of concepts such as "family resilience," which suggests that families may come out better after successfully facing hardships, increased study of the role of religion in family life, and the social contexts of war and economic disaster. The model uses social systems theory and insights from family sociological research in its framework and approach. In this model, the family unit is seen as a system that must maintain equilibrium in order to function and provide adequate material and emotional resources to its members. The stressor event creates a disturbance of family equilibrium such that the family system must somehow re-establish equilibrium in order to avoid dysfunction. The family system can also be conceptualized as a social group or organization with specific functions. "The family system is an organization consisting of intricately related social positions that have complex sets of roles and norms." The existence of family dysfunction presents a crisis situation for families. In other words, crisis occurs in families when, due to the stress of a change or event, they fail to provide such functions as socialization, reproduction, resource sharing, and emotional support. The family system contains inputs and outputs that are represented by the specific variables in the $\mathrm{ABC}-\mathrm{X}$ model. The exogenous variables include (A) the specific stressor event, (B) the family's available resources, and $(\mathrm{C})$ perceptions of the event. The endogenous variable $(\mathrm{X})$ of the $\mathrm{ABC}-\mathrm{X}$ model is the degree to which the stressor precipitates a crisis to the extent that a family can no longer remain intact and functional. Variable A of the ABC-X model represents the stressor or stressful situation or event faced by a family. A stressor can be any change in a family's social context or norms including those with both positive and negative aspects, such as an occupational change that entails both an increase in monetary resources and increased time and energy demands. Any new situation or event that requires substantial adjustments can be a cause of stress for individual family members, relationships within the family, or the family system as a whole. Family stressors ordinarily consist of occupational, housing, health status, or relationship changes.

Variable B of the ABC-X model describes the resources available to a family, which can help it evade crisis when facing a stressor. Without access to the appropriate resources, families are more likely to experience crisis when encountering a stressor. Individual-level psychological resources such as selfesteem and familial resources such as family integration and mutual adaptability can enable families to cope with stress events. Variable C describes a family's perceptions or definitions of a stressful situation or event. Variable $\mathrm{X}$ in the model thus represents the amount of crisis that occurs as an outcome of the stressor event's interaction with a family's available resources and perceptions of the stressor. For families with adequate resources and perceptions, a stressor may not create any crisis at all. A crisis occurs when the family, due to a lack of appropriate available resources and inability to functionally define the stressor, fails to cope with the stressor, causing dysfunction, disorganization, or disruption [59].

MR is a condition of disability characterized by limitations in intellectual function and adaptive behavior, especially in conceptual, social and adaptive skill. Children mentally retarded have limited mental function, communication skills, ability to maintain themselves and independence during the period of development [60-62]. Children with mental retardation require intensive care by parents to optimize their developmental stages such as conducting medical examinations, counseling and coaching [63].

\section{RISK FACTORS OF ID}

Intellectual disability may be caused by a problem that begins any time before the child completes their 18th year - even before they are born it may result from a problem in the brain, injury, or disease ${ }^{(64)}$. It is associated with multi-causal risk factors including genetic and non-genetic or acquired causes. But in some cases, the etiology is unknown [65]. Genetic factors such as chromosomal abnormalities, inherited genetic traits, and single gene disorders are the major causes accounting for $30 \%$ to $50 \%$ of all intellectual disability cases. Non-genetic causes comprise prenatal, perinatal, postnatal, and environmental factors [66]. Most prevalent reported non-genetic prenatal risk factors include maternal conditions such as asthma, diabetes, hypertension, renal conditions, and epilepsy [66, 67]. Other factors are tobacco or alcohol use parental advanced age, low maternal education, multiparty, and maternal black race [66]. Main perinatal factors are low birth weight, preterm birth, birth complications, and perinatal infections ${ }^{(66-68)}$. Postnatal infections, exposure to toxicants like lead or mercury, developmental disorders, central nervous system malignancies, and chronic severe malnutrition have been reported as postnatal factors $[65,66]$. These associated factors of intellectual disability are in interactive complexity with environmental factors and socio-demographic and socioeconomic characteristics of population [67-69]. It is that many of the factors and causes of non-genetic intellectual disability are preventable, if early detection is done and timely interventions are taken [70]. Most of the studies regarding risk factors of intellectual 
disability have been conducted in developed countries, with limited information from developing countries [71].

\section{DIAGNOSIS OF ID}

Based on the fact that DSM-5 (Diagnostic and Statistical Manual of Mental Disorders, Fifth Edition) criteria specify that diagnosis of intellectual disability is made during development period, before age of 18 years [72]. High prevalence rates in South Africa for conditions that are associated with onset of intellectual disability in the prenatal and developmental period would suggest a higher total prevalence of intellectual disability than in developed countries [73]. Intellectual assessment in autistic preschoolers is the few IQ tests, and One of the most widely used cognitive tests in preschool autistic children is the Mullen Scales of Early Learning (MSEL) [74].

\section{TREATMENT OF ID}

Anti-epileptic such as Gaba-pentine and lamotrigine are broadly considered safe treatment for epilepsy in people with an ID [75]. The atypical antipsychotics Risperidone and aripiprazole are currently the only medications approved by the United States Food and Drug Administration (FDA) for the treatment of irritability associated with ASD [76].

\section{COMPLICATIONS OF ID}

Dysphagia in people with intellectual disability appears to be associated with more severe levels of intellectual disability, co morbid cerebral palsy, and motor impairments [77]. Impaired gas exchange at birth is risk of intellectual disability and autism [78]. Obesity prevalence for children with ID was $28.9 \%$ and $15.5 \%$ for children without ID [79]. Anxiety is common in youth with autism spectrum disorder [80].

\section{NURSES ROLE IN THE MANAGEMENT OF BURDEN OF CAREGIVERS OF CHILDREN WITH IDD}

Nursing in the field of intellectual and developmental disability (IDD) has evolved over the last decade. With this evolution new challenges related to this field of nursing practice have surfaced. The field of IDD nursing is complex and considered out of the realm of common nursing practice. IDD nursing is a specialized area of nursing focused on the complex healthcare needs of this population. This field of nursing requires a wide range of specified skills in order to meet the varied health, behavioral, advocacy, and societal needs of persons with IDD. Nurses replied in the study by Sowney and Barr that they received no formal education or practice experience with the disability population prior to providing nursing care. Additionally, McKeon's findings determined that community nurses regarded their knowledge and skill related to caring for those with intellectual disability as inadequate and noted a need for knowledge and skill training specifically related to disability nursing care. In the author's personal experience this was a common theme. The lack of knowledge may be a barrier to ensuring quality care for persons with IDD. Nursing knowledge deficit also places an undue burden on the nurses who support them [81].

The nurse's role is to establish a caring relationship with patients and treat patients' holistically, that is, body, mind and spirit. Through the nurse's attitude and competence, a patient's world can become larger or smaller, brighter and drab, rich or dull, threatening or secure. This means that patients' quality care depends mainly on two aspects, namely, attitude and competence, meaning that a nurse with positive attitude and who is competent can provide first class patient care. Nursing care for individuals with developmental disabilities is focused on assisting them to attain and maintain an optimal state of wellness across their natural life span. The nurses who care for ID patients experience stress and that has serious implications for nurse's well-being, for people with ID and for services. In terms of the implications for staff, recent surveys have suggested that around one-third of staff working in adult services experience stress at levels indicative of the presence of a mental health problem [82].

The nurse assesses the patient on levels of characteristics, which include resiliency, vulnerability, stability, and complexity. The family is included when the nurse is assessing the (a) availability of resources which may be financial, or support systems, (b) the ability to participate in care, (c) the ability to participate in decision making and (d) the predictability or trajectory of illness. The areas of competency assessed of the nurse include (a) the ability to use critical thinking skills to make clinical decisions, (b) the ability to advocate for the patient and family, to be able to assist with coming to a resolution of ethical issues, (c) to be able to identify the patient or family current or future needs, (d) to promote interdisciplinary collaboration to achieve the best outcomes for the patient and family, (e) the ability to negotiate through the health care system and has knowledge of available resources, (f) to achieve cultural awareness, (g) the ability to assess the education needs of the patient or family and provide the teaching in a manner the patient or family will understand [82].

\section{REFERENCES}

1. Hailemariam KW. The Psychological Distress, Subjective Burden and Affiliate Stigma among Caregivers of People with Mental Illness in Amanuel Specialized Mental Hospital. American Journal of Applied Psychology 2015; 4 (2): 35-49.

2. http://www.unicef.org/sudan/Key_Facts_CChildren_ with_Disabilities_in_Sudan.pdf.

3. Yu J, Yap P, Liew TM. The optimal short version of the Zarit Burden Interview for dementia caregivers: diagnostic utility and externally validated cutoffs. 
Aging and Mental Health 2018 Doi: 10.1080/13607863.2018.1450841.

4. Seng BK. Validity and Reliability of the Zarit Burden Interview in Assessing Care giving Burden. Annual of the Academy of Medicine, Singapore 2014; 39 (10): 758- 763.

5. Ohayon H, Pijnenborg GHM, Ben-Pazi S, Goldzweig TG. Coping with information style and family burden: Possible roles of self-stigma and hope among parents of children in a psychiatric inpatient unit. European psychiatric 2017; (42): 8-13.

6. Peer JW. Hillman SB. Stress and Resilience for Parents of Children with Intellectual and Developmental Disabilities: Journal of Policy and Practice in Intellectual Disabilities 2014; 11 (2):9298.

7. Burke MM, Heller T. Disparities in Unmet Service Needs among Adults with Intellectual and Other Developmental Disabilities; Journal of Applied Research in Intellectual Disabilities. Published for the British Institute of disability by Wiley and Sons 2016.

8. Burke MM, Lee C, Arnold CK, Owen A. The Perceptions of Professionals toward Siblings of Individuals with Intellectual and Developmental Disabilities; intellectual and developmental disabilities 2017; 55 (2): 72-83.

9. Tara L B, Andrea NW. Psychometric Properties of Two Measures of Crisis and Distress in Parents of Children with Intellectual and Developmental Disabilities. Journal of mental health research in intellectual disabilities 2017; 10 (1): 30-49.

10. Wakimizu R, Yamaguchi K, Fujioka H. Family empowerment and quality of life of parents raising children with Developmental Disabilities in 78 Japanese families. International Journal of Nursing Sciences 2017; (4): 38-45.

11. Stewart S L, Hassani KF, Poss J, Hirdes J. The determinants of service complexity in children with intellectual disabilities. Journal of Intellectual Disability Research 2017; 61(11): 1055-1068.

12. Ngo H, Shin JY, Nhan NV, Yang LH. Stigma and restriction on the social life of families of children with intellectual disabilities in Vietnam: Singapore Med J. 2017; 53(7): 451.

13. Grover $\mathrm{S}$ et al. Stigma experienced by caregivers of patients with severe mental disorders; International Journal of Social Psychiatry 2017; 63(5): 407-417.

14. DSM is the manual used by clinicians and researchers to diagnose and classify mental disorders. The American Psychiatric Association (APA) will publish DSM-5 in 2013, culminating a 14-year revision process. Www.DSM5.org.

15. Marty M.A, Segal LD. DSM-5: Diagnostic and Statistical Manual of Mental Disorders. Research Gate 2015. http://researchgate.net/publication/283296361.

16. Nemerimana M, Chege MN, Odhiambo EA. Risk Factors Associated with Severity of Non-genetic Intellectual Disability (Mental Retardation) among Children Aged 2-18 Years Attending Kenyatta National Hospital. Neurology Research International; Article ID 2013; 6956703, 11 pages. https://doi.org/10.1155/2018/6956703.
17. WHO. International Classification of Diseases mortality and morbidity statistics 2018; Page 1-9.

18. Al-Dujaili A H, Al-Mossawy D. Psychosocial burden among caregivers of children with autism spectrum disorder in Najaf province. Curr Pediatr Res 2017; 21 (2): 272-282.

19. Hidayah R, Lestari R. Effects of self-help groups' intervention on coping strategies of parents of children with autism spectrum disorder. International Journal of Public Health Science 2019; 8 (1): 20-25.

20. Al-Dujaili AH, Al-Mossawy DA. Psychosocial burden among caregivers of children with autism spectrum disorder in Najaf province. Curr Pediatr Res 2017; 21 (2): 272-282. www.currentpediatrics.com

21. Maroon EL, rEDolar-ripoll D, BoixaDos ME etal. Burden on Caregivers of Children with Cerebral Palsy. Univ. Psychol 2013; (12) 3: 767-777.

22. Ramita Sardana US, Sumalatha KB. Family life of caregivers: A descriptive study of disruption of family activities, leisure's and interaction of caregivers of children with cerebral palsy. Al Ameen J Med Sci 2016; 9(3):154-161.

23. Marchal JP. Health related quality of life in parents of six to eight year old children with Down syndrome. Research in Developmental Disabilities 2013; (34): 4239-4247.

24. Anna JE, Seltzer MM. Accounting for the "Down syndrome advantage 2011: 116(1):3-15.

25. Moreira RM, de Oliveira BG, Cruz DP et al. Quality of life of family caregivers of people with Down syndrome. Care Online. Jul/set 2016; 8(3):48264832. DOI: http://dx.doi.org/10.9789/21755361.2016.v8i3.4826-4832.

26. Povee K, Roberts L, Bourke J, Leonard H. Family functioning in families with a child with Down syndrome. Journal of Intellectual Disability Research 2012; 56 (10): 961-973.

27. Jensen MP, Brunklaus A, Dorris L, Zuberi SM, Knupp KG, Galer BS, Gammaitoni AR. The humanistic and economic burden of Dravet syndrome on caregivers and families: implications for future research. Epilepsy and Behavior 2017; 70(A): pp. 104-109. (doi:10.1016/j.yebeh.2017.02.003).

28. Ioannis K, Georgia DM, Chairwomen P, Marta San L, Kim ford JM, Andrew JC. The effect of epilepsy surgery on caregiver quality of life. Epilepsy Research 2013; (107):181-189.

29. Yusuf AJ, Nuhu FT, Olisah VO. Emotional distress among caregivers of patients with epilepsy in Katsina State, Northern Nigeria. Afr J Psychiatry 2011; (16): 41-44.

30. Jeffrey MC, Paul AM. Family burden, child disability, and the adjustment of mothers caring for children with epilepsy. Epilepsy \& Behavior 2017; (68): 168-173.

31. Salmiah S. having children with mental retardation. International journal of public health science 2010; 6(4): 331-336.

32. Judarwanto W. Mental retardation prevention and treatment. International journal of public health science 2009; 6(4): 331-336. 
33. Somantri S. Having children with mental retardation. Psychology of exceptional children 2012; 6(4): 331336

34. Caldwell JA. Predictors of resilience in families of adults with intellectual and developmental disabilities following deinstitutionalization. MSc. Thesis, Oklahoma State University, Oklahoma 2017.

35. Suedan A. Imagined Disclosure of a Close other's Mental Health Status: A Strategy for Reducing Stigma by Association. MSc. Thesis Laurentian University Sudbury, Ontario, Canada 2018.

36. Feldman DB. Dimensions of mental illness stigma: what about mental illness causes social rejection; journal of social and clinical psychology 2007; 26 (2):137-154.

37. Weastell K. Raising a Child with an Autism Spectrum Disorder: The Experience of Stigma by Association, its Impact on Caregiver Wellbeing, the Influence of Signature Strengths, and the Experience of Growth. PhD. Thesis, Massey University, Manawalu, New Zealand 2017.

38. Cantwell J, Muldoon O, Gallagher S. The influence of self-esteem and social support on the relationship between stigma and depressive symptomology in parents caring for children with intellectual disabilities. Journal of Intellectual Disability Research 2015; 59 (10): 948-957.

39. Jenny LD, Manago B. Motherhood and Associative Moral Stigma. Stigma and Health 2017; 1 (2): 72-86.

40. Mandleco B, Freeborn D, Tina Dyches. Caregiver Burden and Sibling Relationships in Families Raising Children with Disabilities and Typically Developing Children. 2014; 32 (2): 241-246.

41. Fairthorne J, de Klerk N, Leonard H. Brief Report: Burden of Care in Mothers of Children with Autism Spectrum Disorder or Intellectual Disability. J Autism Dev Disord 2015; DOI 10.1007/s10803-0152629-9

42. Heller T, Gibbons HM, Fisher D. Care giving and Family Support Interventions: Crossing Networks of Aging and Developmental Disabilities. Intellectual and developmental disabilities 2015; 53 (5): 329-345.

43. Mwale CM, Kauye F, Gladstone M, Mathanga D. Prevalence of psychological distress among parents of children with intellectual disabilities in Malawi. BMC Psychiatry 2018 ; (18): 146.

44. Jillian MG, Totsika V, Richard PH. Physical and psychological health of family carers' co-residing with an adult relative with an intellectual disability 2017; DOI: $10.1111 /$ jar. 12353

45. Kerenhappachu MS, Godishala S. Care Giver's Burden and Perceived Social Support in Mothers of Children with Mental Retardation; International Journal of Scientific and Research Publications. 2014; 4 (4): 2250-3153

46. Marshall J, Tanner JP, Kozyr YA, Kirby RS. Services and supports for young children with Down syndrome: parent and provider perspectives. Child care health and development 2014; Doi: 10. 111/cch.12162, 9 pages.

47. Johansson A, Andershed B, Anderzen-Carlsson A. Conceptions of mental health care - from the perspective of parents' of adult children suffering from mental illness; Scandinavian Journal of Caring Sciences

http://urn.kb.se/resolve?urn=urn:nbn:se:oru:diva-

34617.

48. Anne VK, Tamira JW, Grace TB. Caregiver Strain and Sensory Features in Children with Autism Spectrum Disorder and Other Developmental Disabilities; American Journal on Intellectual and Developmental Disabilities 2015; 120 (1):32-45.

49. Garg R, Arun P, Chavan B S. Stigma among Caregivers of Persons with Psychiatric Disorders. Indian Journal of Medical Science 2017; 69 (2): 15 22.

50. Ivona MV, Oliver T, Nada D, Marija C. Experienced and Anticipated Discrimination in Persons with Physical Disabilities in Serbia. European Journal of Interdisciplinary Studies 2017; 7 (2): 65-74.

51. Littin SL, Blacher J. Young adults with severe intellectual disability: Culture, parent, and sibling impact. Journal of intellectual \& developmental disability 2016; http://dx.doi.org/10.3109/13668250.2016.1230843.

52. Lunsky Y, Robinson S, Blinkhorn A, Kuntz HO. Parents of Adults with Intellectual and Developmental Disabilities (IDD) and Compound Care giving Responsibilities. J Child Fam Stud 2017; (26):1374-1379.

53. Daniel MB, Sheila ME. Parent-Child Interaction Therapy for Disruptive Behavior in Children with Mental Retardation: Journal of Clinical Child and Adolescent Psychology 2007; 36 (3): 418-429.

54. Dabrowska A, Pisula E. Parenting stress and coping styles in mothers and fathers of pre-school children with autism and Down syndrome Journal of Intellectual Disability Research 2010; 54 (3): p 266.

55. Kiri AP, Ware R, McPherson L, Emerson E, Lennox N. Parent-Related Stress of Male and Female Carers of Adolescents with Intellectual Disabilities and Carers of Children within the General Population. Journal of Applied Research in Intellectual Disabilities 2016.

56. Natasha JB. Quality of Life for Caregivers of a Child aged 6 - 16 years with Autistic Spectrum Disorder and/or an Intellectual Disability. MSc. Thesis, Massey University, Turitea, New Zealand 2010.

57. Carol I, Tsao P, Tummala A, Roberts LW. Stigma in Mental Health Care Academic Psychiatry 2008; 32 (2). http://ap.psychiatryonline.org

58. Sethi S, Subhash CB, and Dhiman V. Study of level of stress and burden in the caregivers of children with mental retardation. Eastern Journal of Medicine 2007; (12): 21-24.

59. Rosino M. ABC-X model for family stress and coping 2017; DOI: 10.1002/9781119085621.wbefs313.

60. Kishore MT. Parenting children with mental retardation; determinants of positive coping and functioning. Bio-psycho-social issues in positive health 2014: 330-338.

61. Fadilah M. Relation's role of parents with children independence level mental retardation in YPAC Palembang. IJPHS 2014; ISSN 2252-8806 
62. The ministry of social affairs, social welfare development, Jakarta. IJPHS 2012; 6(4): 331-336.

63. Jannah M, Anita N. Experience of parents who have children mental retardation in pekaloongan city. IJPHS 2012; 6(4): 331-336.

64. James GL, Chuaqui J, Debra RW, Emanuel A. The Global Impact of Intellectual Disability and Other Mental Disorders in Children, International Journal of Childbirth Education 2019; (34) 2: 4pges.

65. Armatas V, "Mental retardation: definitions, etiology, epidemiology and diagnosis " Journal of Sport and Health Research 2009; 1(2):112-122

66. Huang J, Zhu T, Y Qu, D Mu. "Prenatal, perinatal and neonatal risk factors for intellectual disability. A systemic review and meta- Analysis," PLoS ONE, 2016; 11(4): Article ID e 0153655.

67. Leonard H, Klerk ND, Bourke J, and Bower C. "Maternal health in pregnancy and intellectual disability in the offspring: a population-based study." Annals of Epidemiology 2006; (16) 6: 448-454.

68. Bilder DA, Pin borough-Zimmerman J, Bakian AV et al. "Prenatal and perinatal factors associated with intellectual disability." American Journal on Intellectual and Developmental Disabilities 2013; (118) 2: 156-176.

69. Sharma S, Raina SK, Bhardwaj AK, Chaudhary S, Kashyap V, Chander V. "Socio demography of mental retardation. A community-based study from a goiter zone in rural sub-Himalayan India," Journal of Neurosciences in Rural Practice 2015; (6) 2: 165169.

70. Chapman DA, Scott KG, Mason CA. "Early risk factors for mental retardation. Role of maternal age and maternal education," American Journal on Intellectual and Developmental Disabilities 2002; (107) 1:46-59.

71. Maulik PK, Harbour CK. "Epidemiology of intellectual disability." International Encyclopedia of Rehabilitation 2010 http://cirrie.bufalo.edu/encyclopedia/en/article/144.

72. American Psychiatric Association (APA), Diagnostic and Statistical Manual of Mental Disorders, (DSM-5), American Psychiatric Publishing, Washington, DC, USA, 5th edition, 2013.
73. Colleen MA. Perspectives of intellectual disability in South Africa: epidemiology, policy, services for children and adults 2010; (23):436-440

74. Courchesne V, Girard D, · Jacques C, Soulieres. Assessing intelligence at autism diagnosis: Journal of Autism and Developmental Disorders 2018; https://doi.org/10.1007/s10803-018-3786-4.

75. Doran $\mathrm{Z}$ etal. Prescribing for epilepsy in adults with Intellectual Disability 2016; 19 pages.

76. Loebe A et al. Lurasidone for the Treatment of Irritability Associated with Autistic Disorder. J Autism Dev Disord 2016; (46):1153-1163 DOI 10.1007/s10803-015-2628-x

77. Janet R, Darren C, Susannah B, Eric E, Chris H. Prevalence of Dysphagia in People with Intellectual Disability: A Systematic Review. Intellectual and Developmental Disabilities: December 2017; 55(6): pp. https://doi.org/10.1352/1934-9556-55.6.377

78. Hossein A, bernia M, Mollon J. Impaired Gas Exchange at Birth and Risk of Intellectual Disability and Autism. Journal of Autism and Developmental Disorders 2016; (46) I5: 1847-1859.

79. Segal $\mathrm{M}$ et al. Intellectual disability is associated with increased risk for obesity in a nationally representative sample of U.S. children Disability and Health Journal 2016; (9) 3: 392-398.

80. Christopher AT, Michael GA. Using qualitative methods to guide scale development for anxiety in youth with autism spectrum disorder 2015, https://doi.org/10.1177/1362361315601012

81. Kathy A. intellectual and developmental disability nursing. Nursing: Research and Reviews 2018 ;(8): 23-28

Mandela S P. Experiences of nurses who care for patients with severe/profound intellectual disabilities at a level 3 Psychiatric hospital in the Western Cape. A mini-thesis submitted in partial fulfillment of the requirements for the Degree of Master in the School of Nursing, Faculty of Community and Health Sciences, University of the Western Cape. 2013; 100pages.

82. Harmon, Donna, "Caring for the adult with intellectual disabilities in the acute care setting" (2017). Doctor of Nursing Practice (DNP) Projects. 102. http://scholarworks.umass.edu/ nursing - dnp capstone.

Cite This Article: Amel Ahmed Hassan et al (2021). Burden on Parenting of Children with Special Needs: Review Article. EAS J Nurs Midwifery, 3(2), 63-75. 